\title{
The Open Library. Financial and Human Aspects
}

\author{
by ELMAR MITTLER
}

The year 2000 Seminar of the LIBER architecture group in Warsaw provided an opportunity to discuss new frontiers in the development of library buildings. New ways of financing are needed in an economically fast changing world. It was impressive to hear from Robert Rzesos about the successful financing activities for the University library of Warsaw. Alan MacDougall gave an outstanding paper concerning successful fundraising activities for new library buildings, based on experiences he has made in Dublin. Graham Bulpitt gave an overview on income generation through library buildings.

In the Warsaw University library the participants were provided with a concrete example for activities of this kind: Shops and offices are rented out; and the biggest part of the first underground floor, which will become an area for bookshelves in future, is currently used as a Bowling Arena. In the first instance, it was a culture shock to go immediately from the conference center to this area of public entertainment. But later on we understood, that the provision of other uses is not only a financial necessity, but also provides an additional chance for the library to attract new users and for the users (and the conference participants) to relax during sporting activities.

Other, quite different, examples as to how additional activities in new buildings can give libraries a new popularity were illustrated by the Royal Library in Copenhagen (Steen Bille Larsen) and the Bibliothek der Großen Kirche in Emden (Walter Schulz), if also as side effects - the noise in the building for the arrangement of a concert or a candle light dinner may disturb the main tasks of the library at times.

Libraries, which want to raise funds, need a clear vision. It was impressive to see

- how our colleagues in Warsaw used the new building for a thorough modernisation of all their practices (Henryk Hollender, Ian Butchert); 
- how Dublin University Library is promoting her active role in the educational mission of the university (Paul Sheehan);

- how Vera Vohlidalova - together with the architect Radim Kousal - is in Liberec (Czech Republic) realising an outstanding building combining an open access library with a Jewish religious center, providing a visible monument for reconciliation.

There are outstanding examples of new library architecture, which were presented at this seminar. The most impressive was - without any doubt - the new building of the Warsaw University Library itself (Marek Budzynski). It is a striking combination of monumentality and functionality. It is an extraordinary example of modern library architecture in its arrangement of public areas for lending and studying as well as it's provision for private spaces to allow concentrated work of readers and staff. It was the right decision of the Steering Committee to choose Warsaw for the Seminar 2000. The participants of the Paris Seminar correctly foresaw that the Warsaw library will be an outstanding example of post-modern library architecture - including also some ecological aspects of modern building design. ${ }^{1}$

Ewa has prepared the very well done documentation of new European library buildings, the material for which was collected from the members of the Steering Committee of the Architecture Group. ${ }^{2}$ Unfortunately not all papers of the conference were delivered on time. Therefore this publication cannot document the entire programme. But even if all texts had been provided, they could not mirror the real experience of physical visits and the value of interesting discussions at the conference itself.

All participants would like to thank the library director Henryk Hollender, Ewa and the whole team of the Warsaw library for their excellent organisation and their warm hospitality. Last but not least, I would like to thank the colleagues and architects in Kattovice and Krakow for hosting us during the pre-conference tour, as well the National Library and the Technical University Library in Warsaw, which gave us additional useful insights into the workings of Polish librarianships and into Polish library architecture.

It was worth travelling to Warsaw and Poland! 


\section{REFERENCES}

1 Anna Chmura, Ewa Kobierska-Maciuszko. European Research Cooperation 7 (1997) p. 276-286.

2 Ewa Kobierska-Maciuszko (Ed.): The open library. Documentation of the new buildings in Europe. Warsaw: University Library 2000.

Prof. Dr. Elmar Mittler

President of LIBER

Niedersächsische Staats- und Universitätsbibliothek

Platz der Göttinger Sieben 1

37073 Göttingen, Germany

sub@mail.sub.uni-goettingen.de 